\title{
CNS inflammation and neurodegeneration
}

\author{
Tanuja Chitnis and Howard L. Weiner \\ Ann Romney Center for Neurological Diseases, Department of Neurology, Brigham and Women's Hospital, Harvard Medical School, Boston, Massachusetts, USA.
}

\begin{abstract}
There is an increasing recognition that inflammation plays a critical role in neurodegenerative diseases of the CNS, including Alzheimer's disease, amyotrophic lateral sclerosis, Parkinson's disease, and the prototypic neuroinflammatory disease multiple sclerosis (MS). Differential immune responses involving the adaptive versus the innate immune system are observed at various stages of neurodegenerative diseases, and may not only drive disease processes but could serve as therapeutic targets. Ongoing investigations into the specific inflammatory mechanisms that play roles in disease causation and progression have revealed lessons about inflammation-driven neurodegeneration that can be applied to other neurodegenerative diseases. An increasing number of immunotherapeutic strategies that have been successful in MS are now being applied to other neurodegenerative diseases. Some approaches suppress CNS immune mechanisms, while others harness the immune system to clear deleterious products and cells. This Review focuses on the mechanisms by which inflammation, mediated either by the peripheral immune response or by endogenous CNS immune mechanisms, can affect CNS neurodegeneration.
\end{abstract}

\section{Introduction}

Increasing appreciation for the role of inflammation in neurodegenerative diseases of the CNS, including Alzheimer's disease (AD), amyotrophic lateral sclerosis (ALS), Parkinson's disease (PD), and the prototypic neuroinflammatory disease multiple sclerosis (MS), has identified differential immune responses involving the adaptive versus the innate immune systems at various stages of disease. These responses may not only drive disease processes but could serve as therapeutic targets. An increasing number of immunotherapeutic strategies that have been successful in MS are now being applied to other neurodegenerative diseases. Some approaches suppress CNS immune mechanisms, while others harness the immune system to clear deleterious products and cells. This Review focuses on the mechanisms, cellular functions, signaling molecules, immune responses, and mediators through which inflammation affects CNS neurodegeneration, and identifies the therapeutic opportunities within these processes.

\section{Mechanisms of neurodegeneration}

Several basic mechanisms that drive neurodegeneration may be triggered by inflammatory cells and their mediators at various stages of the neurodegenerative cascade.

Apoptosis. Apoptosis is caspase-mediated programmed cell death (1) characterized by formation of membrane-enveloped apoptotic bodies that are rapidly phagocytosed by macrophages

Conflict of interest: T. Chitnis has received research funding from Verily, Serono, and Biogen. She has served as a consultant or on the advisory board for Novartis, Sanofi, Genentech, Bayer, and Biogen. H.L. Weiner has received research funding from Verily, Serono, Biogen, Genentech, and Sanofi-Genzyme. He serves on the scientific advisory board for Tiziana and MedDay.

Reference information: J Clin Invest. 2017;127(10):3577-3587.

https://doi.org/10.1172/JCI90609. or neighboring cells. There is evidence of apoptotic mechanisms in animal models of several neurodegenerative diseases, but evidence in human tissues is limited. Caspase-1, $-3,-8$, and -9 activation and cytochrome $c$ release seen in models of Huntington's disease (HD) were also demonstrated in human striatal brain tissue $(2,3)$. Similarly, caspase activation and neuronal apoptosis have been demonstrated in ALS (4) and HIV-associated neurodegeneration (5).

Necroptosis. Necroptosis represents a form of programmed cell death that is independent from the caspase activation and involves loss of plasma membrane integrity. Two main effector proteins of necroptosis are receptor-interacting serine/ threonine-protein kinase 1 (RIPK1) and mixed-lineage kinase domain-like (MLKL). Astrocytes release TNF- $\alpha$, FasL, and TRAIL, which can trigger necroptosis through RIPK1 and MLKL activation, and this mechanism has been demonstrated in murine models of ALS (6). RIPK1-mediated axonal pathology was observed in pathological specimens from ALS patients (7). Necroptotic mechanisms were also observed in MS pathological samples (8).

Neuronal autophagy. Autophagy, also known as type II programmed cell death, is characterized by the accumulation of autophagic vacuoles during cell death, along with toxic components such as proteins or damaged organelles $(9,10)$. Excessive autophagy may lead to self-destruction and cell death. Autophagosomes were identified in affected neurons of patients with $\mathrm{AD}, \mathrm{HD}$, and PD (11-13). Many stimuli also induce autophagy, including nutrient starvation, mitochondrial toxins, hypoxia, and oxidative stress (14).

Retrograde degeneration. Retrograde degeneration of the proximal neuronal cell body may result from axonal injury or transection and may be associated with various pathological changes in the cell body, including apoptosis (15-17) and chromatolysis of the 


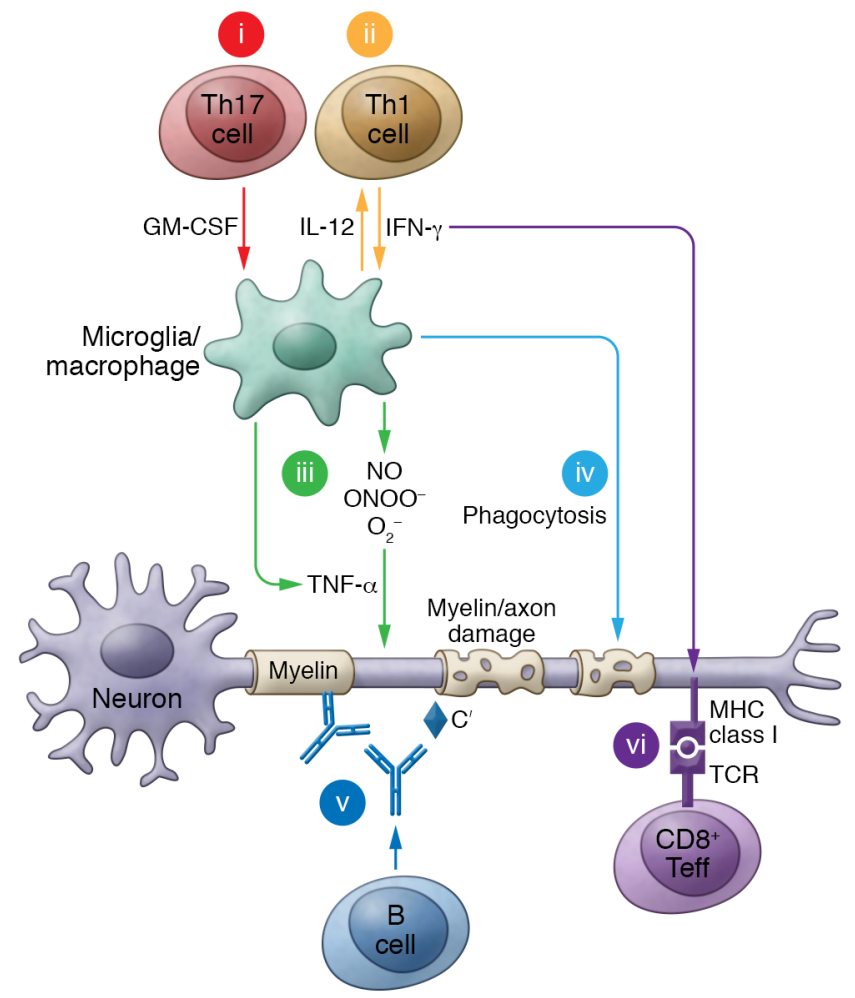

neuronal perikaryon $(18,19)$. The association of neuronal apoptosis with axonal damage suggests that inflammation-induced axotomy may produce retrograde (secondary) death of neuronal cell bodies via apoptosis.

Wallerian degeneration. Proximal damage to the neuron or axon may result in anterograde degeneration of the distal axon, termed Wallerian degeneration. Wallerian degeneration is a cascade of events that includes granular degeneration of the axonal cytoskeleton, accumulation of activated macrophages and microglia, and local changes in the immune environment. Evidence that Wallerian degeneration occurs in MS is seen in a histopathological study demonstrating inflammatory cervicomedullary junction lesion with distal axonal atrophy in the absence of demyelination (20), as well as in MRI studies (21, 22).

Demyelination. The relationship between the oligodendrocyte and axon is complex, with the provision of mutual support through trophic factors that can be disrupted in demyelinating diseases. In addition to protecting the axon from immune-mediated damage $(23,24)$, myelin integrity protects the integrity of the developing axon (25). Myelin-associated glycoprotein (26) and proteolipid protein (27) deliver essential myelin-derived trophic signals to axons (28). Mice lacking proteolipid protein developed axonal swellings and degeneration (27), suggesting that local oligodendroglial support is critical for axon survival.

Astrogliopathy. Dysfunction of astrocytes has broadly been termed astrogliopathy. Aging-related tau astrogliopathy (ARTAG) describes the pathological accumulation of abnormally phosphorylated tau protein in astrocytes that is found in $\mathrm{AD}$, frontal temporal lobe dementias (29), and corticobasal degeneration (30). Neuromyelitis optica (NMO) presents with optic neuritis and myelitis and can mimic MS. NMO is associated with the presence of aqua-
Figure 1. Immune-mediated attack on axons and myelin sheath. During MS and EAE, axonal damage and demyelination are initially mediated by the inflammatory response within the CNS. (i) $\mathrm{CD} 4^{+}$Th17 cells produce GM-CSF, which activates macrophages and microglia. (ii) CD4+ Th1 cells invade the CNS and produce IFN- $\gamma$, which activates macrophages and microglia to produce the cytokine IL-12 (the major promoter of Th1 cytokine production). (iii) Macrophages and microglia also produce nitric oxide (NO), peroxynitrite $\left(\mathrm{ONOO}^{-}\right)$, and superoxide $\left(\mathrm{O}_{2}^{-}\right)$, which are each capable of mediating cellular damage. This capability is enhanced by microglia- and macrophage-derived TNF- $\alpha$ production. (iv) Activated macrophages and microglia may also consume damaged myelin sheaths and axons. (v) B cells produce antibodies that bind to myelin sheaths and may promote complement-mediated damage ( $\left.C^{\prime}\right)$. (vi) IFN- $\gamma$ upregulates the expression of MHC class I by resident CNS cells, potentially inciting a CD8 ${ }^{+}$cytotoxic $T$ cell response.

porin-4 (AQP4) antibodies, which target astrocyte water channels. Pathologically NMO is characterized by extensive loss of immunoreactivity for the astrocytic proteins $\mathrm{AQP} 4$ and glial fibrillary acidic protein (GFAP), perivascular deposition of immunoglobulins, and activation of complement even within lesions with relative preservation of myelin (31).

\section{Immune cells involved in neurodegeneration}

Endogenous CNS immune cells. Inflammation-mediated neurodegeneration may result from dysfunction of endogenous or exogenous immune cells. The two major endogenous cells in the CNS that drive inflammation are astrocytes and mononuclear phagocytes, which include microglia and perivascular macrophages. The mechanisms by which astrocytes and macrophages/microglia drive the neurodegenerative process are outlined in Figure 1, A and B.

Astrocytes. Astrocytes account for almost half of CNS volume. Their normal functions include providing trophic support for neurons, facilitating synapse formation and function, and synaptic pruning by phagocytosis. Astrocytes also help control extracellular ion and neurotransmitter concentrations and maintain the blood-brain barrier (32). One of their most important homeostatic functions is maintaining glutamine-glutamate balance. Glutamate transporters, including EAAT1-EAAT3, are predominantly expressed on astrocytes and neurons and regulate the glutamate uptake and metabolism. Downregulation of these transporters can result in increased extracellular glutamate, potentially enhancing neurotoxicity. Glial expression of these transporters is altered in MS (33) and ALS (34).

Glutaminase converts glutamine to glutamate and is present in astrocytes. Glutaminase is upregulated in MS lesions, colocalizing with infiltrating macrophages and microglia (33), and its expression is correlated with axonal damage. The astrocytic enzymes glutamine synthetase and glutamate dehydrogenase are responsible for glutamate degradation. Both are reduced in MS lesions (33) and spinal cords from mice with experimental autoimmune encephalomyelitis (EAE) (35). Dysfunctional or damaged astrocytes may not perform this function, resulting in increased concentrations of glutamate in the milieu, which may induce NMDA receptor-induced cell death.

Astrocyte function and gene expression are heterogeneous and dependent on local inflammatory milieu as well as region- 


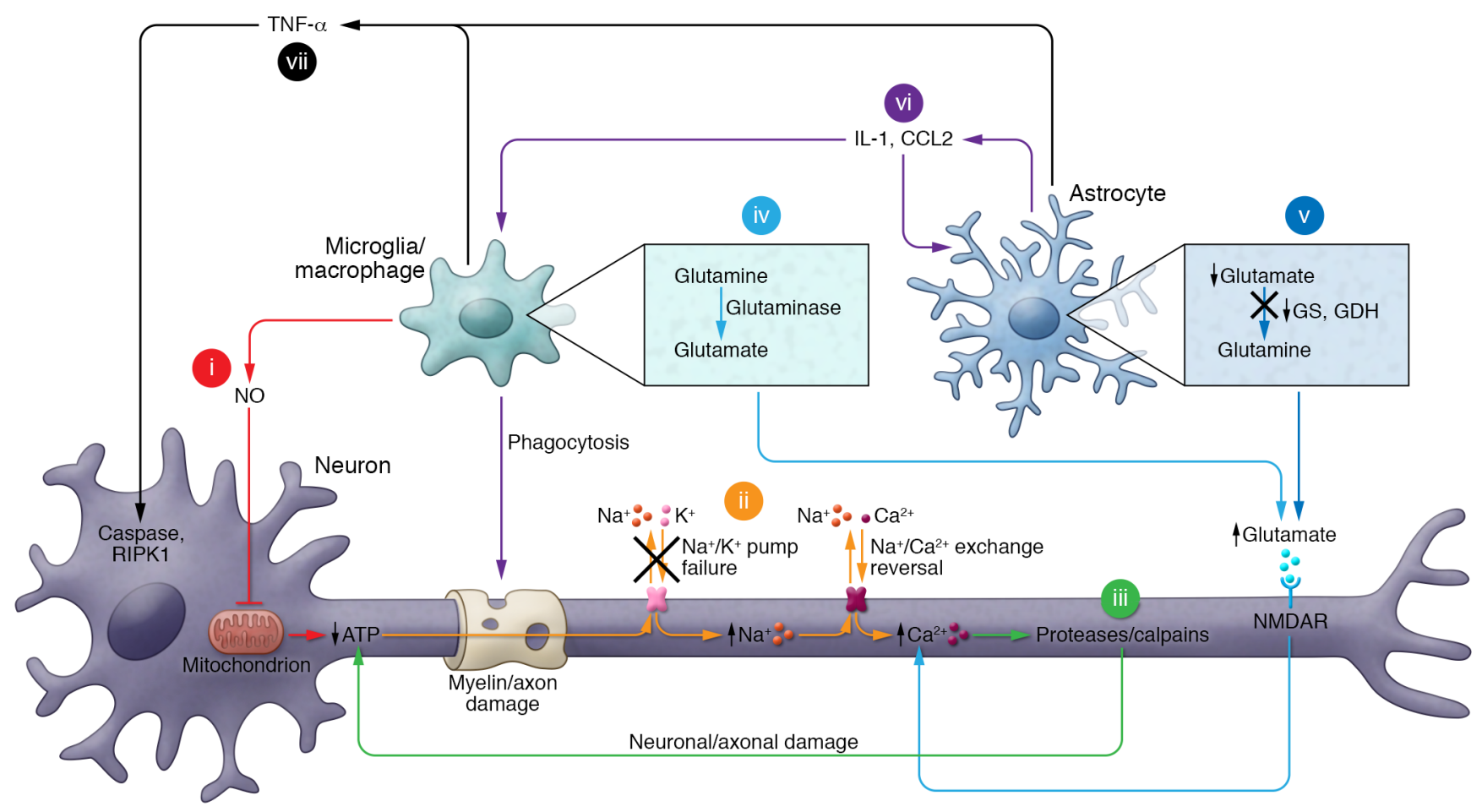

Figure 2. Secondary degeneration of the axon and neuronal cell body. Secondary degeneration may be mediated through several mechanisms. (i) Nitric oxide (NO) produced by macrophages and microglia may inhibit normal cellular respiration and mitochondrial ATP production. (ii) Reductions in neuronal ATP production may lead to failure of the $\mathrm{Na}^{+} / \mathrm{K}^{+}$pump. The subsequent increases in intracellular concentrations of $\mathrm{Na}^{+}$lead to reverse operation of the $\mathrm{Na}^{+} /$ $\mathrm{Ca}^{2+}$ exchanger and opening of voltage-sensitive $\mathrm{Ca}^{2+}$ channels, resulting in a rise of intra-axonal $\mathrm{Ca}^{2+}$. (iii) This, in turn, may activate degradative enzymes, including proteases, phospholipases, and calpains, resulting in further neuronal or axonal damage and impaired ATP production. (iv) Microglia and macrophages recruited to the area produce glutamate, which can interact with NMDA or AMPA receptors, which also cause a rise in intracellular Ca ${ }^{2+}$. (v) Impaired glutamate uptake and degradation in the astrocyte, accompanied by downregulated expression of glutamine synthase (GS) and glutamate dehydrogenase (GDH), perpetuates increased extracellular glutamate levels. (vi) Astrocytes produce CCL2 and cytokines that further activate microglia and macrophages. In turn, microglia and macrophages consume damaged myelin sheaths and axons. (vii) Secondary neuronal cell body degradation can occur by apoptotic or necroptotic mechanisms, triggered in part by immune molecules (e.g., TNF- $\alpha$, TRAIL) that are produced by microglia/macrophages or astrocytes.

and circuit-specific diversity (36-38). Inflamed astrocytes can produce proinflammatory cytokines and chemokines, including CCL2, which recruit monocytes into the CNS and may further activate astrocytes themselves (39). In EAE, astrocytes can have a different role depending on the stage of disease (40). Depletion of astrocytes during acute EAE worsens disease, as astrocytes play a protective role through glutamate metabolism. However, during chronic EAE, astrocytes become inflamed and acquire a pathogenic role; deletion of astrocytes at this stage improves EAE. Lactosylceramide synthesized by $\beta-1,4$-galactosyltransferase 6 is upregulated in the CNS, and lactosylceramide acted in an autocrine manner to control astrocyte transcriptional programs that promote neurodegeneration (40).

Recently, two distinct phenotypes of astrocytes have been described - A1 and A2 (41). A2 astrocytes were predominant in ischemia-induced CNS lesions, while A1 astrocytes predominated in inflammation-induced lesions. TLR4-activated microglia seem to be necessary for A1 astrocyte induction, which is dependent on IL-1 $\alpha$, TNF, and complement C1q in combination. A1 astrocytes expressing downstream complement C3 were identified in CNS specimens from MS, PD, AD, ALS, and HD and may play a key role as mediators of inflammationinduced neurodegeneration (41).

\section{Mononuclear phagocytes}

Perivascular and meningeal macrophages. The CNS contains an extensive network of bone marrow-derived (BMD) mononuclear phagocytes, including macrophages of the meninges, choroid plexus, and perivascular spaces. Perivascular macrophages differ from microglia and from BMD peritoneal macrophages or circulating monocytes. The transcriptional activator MYB is critical for development of BMD monocytes, but perivascular macrophage development depends on PU.1, IRF8, and CSF1R. The unique microenvironments of perivascular macrophages may work to shape their properties, including their CNS macrophage signatures (42-44). In MS, perivascular macrophages may function as antigen-presenting cells to $\mathrm{T}$ cells (45). The accumulation of perivascular macrophages observed in HIV encephalopathy may play an important role in the ensuing neurodegenerative process (46).

Microglia. Microglia are the resident macrophages of the CNS. Derived from the embryonic yolk sac, they migrate into the developing neural tube and subsequently colonize the brain parenchyma (47-49). Microglia turn over slowly and are present throughout the lifespan. They do not repopulate from the BMD myeloid precursors and are independent of blood-derived monocytes. Microglial precursors proliferate independently of MYB and myeloid-lineage hematopoietic stem cells (49). Unique markers and gene signatures 


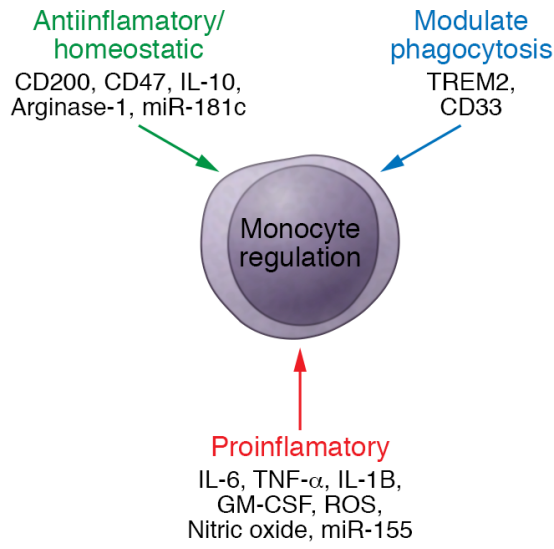

Figure 3. Schema of antiinflammatory, proinflammatory, and phagocytosis-regulating molecules involved in the regulation of CNS monocytes.

that distinguish resident microglia from peripheral mononuclear cells/macrophages (50-52) include FSRSL, P2Y12, TMEM119, CX3CR1, Siglec-H, and the microRNAs miR-99a, miR-125-5p, and miR-342-3p, which are highly expressed in both mouse and human microglia $(50,53)$. Homeostatic microglia are dependent on TGF- $\beta$, and CNS-specific TGF- $\beta$-KO mice develop late-onset motor dysfunction (50), which may be due to impairment of microglia-associated glutamate recycling and synaptic plasticity (54). TMEM119 immunoreactivity is expressed exclusively on a subset of microglia with ramified and amoeboid morphologies in the brains of neurodegenerative diseases, such as $\mathrm{AD}$, whereas infiltrating macrophages did not express TMEM11 9 (55) in demyelinating lesions of MS and necrotic lesions of cerebral infarction (56).

Although microglia have previously been classified as M1 (proinflammatory) and M2 (antiinflammatory), it is now clear that microglia are more complex than this simple dichotomy, as many microglia demonstrate characteristics of both phenotypes (refs. 57, 58 , and Figure 2). A phagocytic program plays an important role in clearing aberrant proteins, particularly in AD, PD, and ALS. More recent work identifies a microglia subtype called "dark microglia" with ramified and thin processes and prominent staining for IBA1, CD11b, and microglia-specific 4D4, as well as TREM2 that associates with amyloid plaques (59). Future studies examining the molecular signatures of microglia in health and disease may identify novel targets for diagnosis and modulation of neurodegenerative diseases.

Invading peripheral macrophages. Blood-derived monocytes can differentiate into macrophages and may invade the CNS to mediate CNS pathology, where they may be difficult to distinguish from resident microglial cells. Blood-derived macrophages associate with nodes of Ranvier and initiate demyelination, whereas microglia appear to clear debris (60). GM-CSF-activated mononuclear phagocytes that migrate into the CNS exhibit a more pathogenic signature than those that migrate to other organs, which may be due to the unique microenvironment of the CNS (61).

\section{Major signaling molecules of CNS mononuclear phagocytes}

CD200-CD200R. CD200 is primarily expressed on the surface of neurons in both the CNS and the PNS, as well as thymocytes, recir- culating B cells, activated B cells, and follicular dendritic cells (62). CD200 receptor (CD200R) initiates tyrosine phosphorylation (63) and is expressed only on cells of the microglia/macrophage lineage $(63,64)$. Administration of a CD200R-blocking antibody to Lewis rats exacerbated EAE (63), and CD200-deficient mice experienced earlier onset of EAE, with increased microglia/macrophage accumulation and activation in the CNS as demonstrated by increased expression of inducible NOS (iNOS) (65). We found that administration of a CD200R1 agonist attenuated disease in a chronic MS model (66). Enhanced CD200 expression was associated with reduced Wallerian degeneration in the slow Wallerian degeneration (Wlds) mouse (67), a spontaneously occurring mutant with the unique phenotype of protection against several forms of axonal injury (68-71). In vitro, Wld ${ }^{s}$ neuronal cultures were protected from microglia-induced neurotoxicity, which was abrogated by anti-CD200 antibody treatment (67).

SIRP $\alpha-C D 47$. SIRP $\alpha$ (also known as SHPS-1, $\mathrm{p} 84$, and BIT) is a regulatory membrane glycoprotein expressed mainly by myeloid cells, stem cells, and neurons. It binds CD47 on microglia to deliver an inhibitory signal $(72,73)$. SIRP $\alpha$ activation was linked to the inhibition of cell activities, including decreased cytokine production, reduced monocyte adhesion to the extracellular matrix, reduced phagocytosis, and maturation arrest in dendritic cells (74-76). SIRP $\alpha$ engagement inhibits macrophage phagocytosis by recruiting SHP-1 (77). Fc $\gamma$ receptor $(\mathrm{Fc} \gamma \mathrm{R})$ activation stimulates the association between SHP-1 and SIRPa, which in turn inhibits Fc $\gamma \mathrm{R}$ - and complement receptor-mediated phagocytosis (75, 78). CD47 expression is downregulated in MS brain lesions (79). Although CD47-deficient mice are resistant to EAE, primarily owing to lack of APC activation, blocking CD47 enhances disease progression by increasing myelin phagocytosis in the CNS (79).

TREM2. TREM2 (triggering receptor expressed on myeloid cells-2) is an activating phospholipid-binding receptor that couples with TYROBP, an adaptor protein, to attenuate inflammatory activation and increase phagocytic clearance of cell debris. DAP12 forms a receptor-signaling complex with TREM2 and triggers activation of immune responses to macrophages and microglia. A rare missense mutation in the gene encoding TREM2 confers risk of late-onset $\mathrm{AD}(80,81)$ and frontotemporal dementia (82), possibly due to impaired clearance of proteins by macrophages and microglia.

CD33. CD33 is an immunoglobulin-like lectin that binds sialic acids and delivers inhibitory signals to human microglia. CD33 is increased in microglial cells in AD brain and inhibits uptake of amyloid by microglial cells (83). The minor allele of the CD33 SNP rs3865444 has been shown to confer protection against $\mathrm{AD}$ (84).

Purinergic metabolites. Dying cells in the brain may release extracellular purinergic metabolites such as ATP and NAD, leading to both innate and adaptive immune activation $(85,86)$. The uptake of double-stranded DNA can induce activation of TLRs. The purinergic receptor P2Y12 is a TGF- $\beta$-responsive molecule uniquely expressed on mouse and human microglia and not on perivascular macrophages or blood-derived monocytes (50), and is expressed predominantly in homeostatic-type microglia (87). $\mathrm{ADP}$ is the endogenous ligand of P2Y12, and homeostatic microglia have increased ligand-mediated calcium responses, which are blocked by selective P2Y12 antagonism (87). 
GM-CSF. GM-CSF stimulates BMD stem cells to differentiate into granulocytes and monocytes. A variety of cells, including macrophages, T cells, mast cells, NK cells, endothelial cells, and fibroblasts, produce GM-CSF, and it can enhance ROS production as well as myeloid cell-mediated phagocytosis. GM-CSF was increased in the cerebrospinal fluid of MS patients (88). In EAE, GM-CSF production by Th17 cells activates effector mononuclear phagocytes (89). GM-CSF-activated mononuclear phagocytes that migrate into the CNS exhibit a more pathogenic signature than those that migrate to other organs, which may be due to the unique CNS microenvironment (61).

MicroRNAs. MicroRNAs (miRNAs) are small noncoding RNAs that function in RNA silencing and posttranscriptional regulation of gene expression (90). While the majority of miRNAs are located within the cell, some miRNAs, commonly known as circulating miRNAs or extracellular miRNAs, function in the extracellular environment. Several miRNAs are associated with microglial function. We have shown that in the SOD1 model of ALS, miR-155 expression was associated with loss of homeostatic microglia signature molecules including P2Y12, TMEM119, OLFM13, the transcription factors EGR1, ATF3, Jun, Fos, and MAFB, and the upstream regulators CSF1R, TGFB1, and TGFBR1, which are essential for microglial survival (91). miR-Let-7a participates in the reduction of nitrite production and the expression of iNOS and IL-6. It also increases expression of brain-derived neurotrophic factor (BDNF), IL-10, and IL-4 in microglia (92). The miRNA miR-181c controls microglia-mediated neuronal apoptosis by suppressing TNF (93).

T cells and neurodegeneration. Th1 and Th17 cells play a major role in the initiation of neurodegeneration in MS by creating an inflammatory milieu and recruiting inflammatory monocytes that lead to axonal damage. T cells may also have a neuroprotective role: we have shown that intranasal administration of anti-CD3 monoclonal antibody in chronic EAE induces an IL-10-secreting Tr1-like cell in the cervical lymph nodes that migrates to the brain, dampens astrocyte and microglial inflammation, and ameliorates neurodegeneration.

$C D 8^{+} T$ cells. $\mathrm{CD} 8^{+} \mathrm{T}$ cells can directly mediate neurodegeneration (Figure 1A). Under inflammatory conditions, IFN- $\gamma$ can induce neuronal expression of MHC I molecules. This may be important in virally mediated reactions as well as in autoimmune diseases, including MS, in which $\mathrm{CD} 8^{+} \mathrm{T}$ cells are found in pathology specimens (94). CD8 ${ }^{+} \mathrm{T}$ cells may also mediate collateral killing of neurons, in part as a result of the release of perforin (and granzymes) independently of Fas/FasL signaling (95). Upon stimulation, $\mathrm{CD}^{+} \mathrm{T}$ cells can upregulate the molecular repertoire for vesicular glutamate release, including glutaminase, which is required to generate glutamate, vesicular proton-ATPase, and vesicular glutamate transporters (96), and thus may be key in immune-mediated neurodegeneration.

$\mathrm{CD}^{+} \mathrm{T}$ cells. Until recently, a direct role of $\mathrm{CD} 4^{+} \mathrm{T}$ cells in neurodegeneration was not appreciated, though they can indirectly initiate neurodegeneration by recruiting inflammatory monocytes. Thus, Th1 and Th17 may be targets to potentially minimize a hostile neuronal microenvironment. The ability of CD $4^{+} \mathrm{T}$ cells to directly mediate cytotoxicity was recently demonstrated in the MPTP-induced mouse model of PD (97). Similar attenuation of
MPTP-induced dopaminergic cell death was seen in mice lacking CD4 as well as in Rag1 $^{-/-}$mice reconstituted with FasL-deficient splenocytes. However, CD8-deficient or $\mathrm{Rag1}^{-/-}$mice reconstituted with IFN- $\gamma$-deficient splenocytes were not protected.

Regulatory $T$ cells. Regulatory T cells (Tregs) include FoxP3 ${ }^{+} \mathrm{C}-$ $\mathrm{D} 25^{+} \mathrm{CD} 4^{+} \mathrm{T}$ cells as well as IL-10-producing Tregs and may play a role in dampening or controlling inflammatory processes within the CNS. Considerable evidence reveals that these cells play a role in the early stages of MS (98). More recent work found that Tregs from ALS patients were less effective in suppressing responder $\mathrm{T}$ lymphocyte proliferation and were increasingly dysfunctional with disease progression $(99,100)$.

\section{Downstream inflammatory mediators of neurodegeneration}

Inflammatory mediators are known to enhance or affect several neurodegenerative mechanisms through key downstream mediators. Others may play neuroprotective roles, as discussed in the next section.

Reactive oxygen and nitrogen species. ROS are chemically reactive chemicals containing oxygen and include peroxides and superoxides. Activated immune cells, particularly macrophages, can produce ROS, which contributes to mitochondrial dysfunction and ultimately neuronal apoptosis. Superoxide dismutase (SOD) binds free superoxide radicals for conversion into molecular oxygen and hydrogen peroxide, the latter of which is then broken down by catalase (101). Over 160 mutations in the SOD gene have been found in forms of ALS $(102,103)$.

Nitric oxide (NO) is a key mediator of neurotoxicity with multiple roles in the CNS. NO is synthesized from L-arginine by NOS and can potently inhibit mitochondrial respiration (Figure 1B). Constitutive forms of NOS are produced by endothelial cells (eNOS) and neurons (nNOS), while the inducible form (iNOS) is produced by a variety of cell types, including macrophages and microglia, in response to inflammatory stimuli. iNOS accounts for the majority of NO production. NO can regulate a variety of cellular processes, including the generation of the highly cytotoxic superoxide anion $\left(\mathrm{O}_{2}{ }^{-}\right)$and peroxynitrite anion $\left(\mathrm{ONOO}^{-}\right)(104,105)$. Collectively, $\mathrm{NO}$ and its products have been shown to mediate neurotoxicity in vitro (106-108), and selective inhibitors of iNOS reduce microglia/ macrophage-mediated neurotoxicity (109).

NO appears to act in concert with other factors in increasing susceptibility to neurotoxicity. In a cerebral ischemia model, the combination of TNF- $\alpha$ and IL- $1 \beta$ was neurotoxic in the presence of iNOS, while in the absence of iNOS, this combination mediated neuroprotection and plasticity (110). Conversely, TNF- $\alpha$ increased neuronal sensitivity toward NO (111). NO inhibits neuronal respiration, which in turn enhances release of glutamate, causing excitotoxic death of neurons (112). Inhibition of iNOS blocked NMDA-mediated neurotoxicity $(113,114)$, reinforcing the concept that NO plays a role in excitotoxicity. Further, arginase can compete with NOS for their common substrate, L-arginine, and thus inhibit NO production. This regulatory mechanism may be important when the extracellular supply of L-arginine is limited (115). Electrically active axons exposed to high concentrations of NO have enhanced susceptibility to persistent conduction block and axonal degeneration $(116,117)$. 
Cytokine-mediated neurodegeneration. It is now well recognized that cytokines secreted by immune cells may have direct neurotoxic properties.

IL-1 is produced by the activated mononuclear phagocyte and upregulated in the CNS during EAE induction (118-120). Injection of its isoform, IL- $1 \beta$, into the rat brain at the time of experimental ischemia or traumatic injury caused increased neuronal cell death and edema (121). Overexpression of IL-1 receptor antagonists in the CNS blocked these effects (122). Addition of IL- 1 in vitro results in neuronal apoptosis (123), and its neurotoxic effects appear to be dependent on iNOS expression $(124,125)$. Thus, IL-1, alone or in combination with iNOS, may be an important factor in neuronal and axonal damage in the CNS. However, IL-1 has also been shown to induce the production of nerve growth factor (NGF) in vitro (126, 127), suggesting some neuroprotective effects.

IL-3 is a cytokine growth factor produced by CD $4^{+} \mathrm{T}$ cells and microglia. It exerts both trophic (128) and toxic effects on neurons $(129,130)$. Systemic overexpression of IL-3 in the CNS of mice results in severe neurological dysfunction characterized by degenerated, vacuolated neurons (131), predominantly motor neurons of the spinal cord, with an increase in inflammatory infiltrates surrounding neurons in the absence of demyelination. In contrast, transgenic IL-3 expression under the astrocytic GFAP promoter resulted in a predominantly demyelinating disease with minimal axonal pathology (132).

IL-6 is secreted by mononuclear phagocytes, T cells, vascular endothelial cells, and fibroblasts in response to IL- 1 and TNF- $\alpha$. Overexpression of IL- 6 in the CNS resulted in neurodegenerative pathology characterized by dendritic vacuolization $(133,134)$. IL-6 orchestrates the transition between innate and adaptive immune responses through the recruitment of monocytes and T cells. In particular, IL- 6 in the presence of TGF- $\beta$ induces Th17 cells (135). IL- 6 also enhances astrogliosis and angiogenesis needed for the tissue remodeling (136).

TNF- $\alpha$ is a proinflammatory cytokine. Local TNF production in the CNS induces oligodendrocyte apoptosis and demyelination in EAE models $(137,138)$. However, TNF- $\alpha$ may play either neuroprotective or neurotoxic roles, depending on expression of other factors including NO $(111,123,124)$, upregulation of NF- $\kappa B$ (139), timing of exposure of damaged neurons to TNF (139), and the presence of excess NMDA receptor agonists (127). In addition, TNF- $\alpha$ may exert neurotoxic effects through inhibition of growth factors such as IGF (140). Interaction of TNF- $\alpha$ with TNF receptor 1 (TNFR1) versus TNFR2 may result in different and even opposite effects. This may explain the unexpected finding that TNF- $\alpha$-deficient mice develop a more severe form of EAE than controls (141). In addition, TNF- $\alpha$ has been shown to promote the proliferation of oligodendrocyte progenitors (142).

Antibody-and complement-mediated neurodegeneration. Antibodies can induce neurodegeneration through two mechanisms, antibody-dependent cell-mediated cytotoxicity (ADCC) and complement-dependent cytotoxicity (CDC). In ADCC, effector immune cells lyse a target cell, whose membrane-surface antigens have been bound or opsonized by specific antibody. The effector cells in this case are typically NK cells, but macrophages, neutrophils, and eosinophils can also mediate ADCC. CDC is a function of the complement system that kills without the involvement of antibodies or cells. Three pathways of complement activation lead to the deposition of membrane attack complexes onto the target, which eventually causes colloid-induced osmotic swelling and lethal membrane damage.

Several studies have demonstrated that complement activation may have neuroprotective effects in specific situations. C3a protects neurons against NMDA toxicity (143). In an in vivo mouse model, C5a protected neurons from kainic acid-induced apoptosis, which was associated with the inhibition of glutamate-mediated caspase induction (144). Some neuronal subtypes, including dentate gyrus granule cells, hippocampal pyramidal hilar cells, and cerebellar Purkinje cells, constitutively express receptors for C3a and C5a $(145,146)$, which may play a role in development.

Neurons express particularly low levels of CD59 and DAF, molecules that normally confer cellular resistance to complement-mediated damage in other organs. Complement deposition is noted in several neuroinflammatory conditions, including NMO (147) and subtypes of MS (148), and may be a downstream therapeutic target.

\section{Immune-directed therapies for neurodegenerative diseases}

Immune-directed therapies for neurodegenerative diseases generally fall into two categories: (a) therapies that target components or cells of the immune system determined to cause disease, such as T cells in MS and microglia in ALS; and (b) therapies that utilize the immune system to clear or target aberrant proteins, including vaccine or passive antibody therapies for $\mathrm{AD}$ and more recently PD. As outlined above, the immune system, and particularly CNS immunity, is composed of many complex interrelated and dependent pathways. Therefore, consideration of upstream and downstream effects of immune-directed therapies is important and can affect a therapy's mechanism of action as well as the risk of adverse events. Below, we discuss lessons learned from the successes and failures of specific immunotherapies for neurodegenerative diseases that provided important insights for developing specific targets of therapy.

Multiple sclerosis. In MS, the initial target is the myelin sheath in the CNS; however, later stages are characterized by microglial activation, astrocytic dysfunction, and secondary neurodegeneration (149). Current immunotherapies for MS target a diverse array of immune cell types of the peripheral immune system, including those of the lymphoid lineage ( $\mathrm{T}$ cells and $\mathrm{B}$ cells) and those of the myeloid lineage (macrophages and dendritic cells). These therapies are most effective during the early relapsing-remitting stage of disease and have only limited efficacy during the later secondary progressive stage of disease, which is thought to be mediated by intrinsic CNS inflammatory and neurodegenerative mechanisms (149) including oxidative stress and axonal degeneration. Some oral immunotherapies, including S1P1 modulators, may penetrate into the CNS, and a recent trial has demonstrated effects in secondary progressive MS (150). S1P1 receptors on astrocytes suppress astrocyte- and microglia-mediated inflammatory pathways $(151,152)$. B cell-directed therapies have a modest effect in primary progressive MS, but it is unclear whether this is due to effects within the CNS or potent modulation of peripheral immune mechanisms (153). An ongoing clinical trial in secondary 
progressive MS evaluates ibudilast, which inhibits macrophage migration inhibitor factor and phosphodiesterase-4 and -10 and thus may modulate microglia and macrophage function (154). A challenge for halting progressive MS is successful targeting of multiple immune-dependent and immune-independent neurodegenerative cascades initiated within the CNS.

Amyotrophic lateral sclerosis. Motor neuron death in ALS often occurs in association with protein inclusions. Familial ALS accounts for $10 \%$ of cases and has been associated with mutations in the SOD1 gene and ubiquitin-related genes (155). Glutamate levels are elevated in ALS patient cerebrospinal fluid, possibly because of aberrant expression of the astrocytic glutamate transporter EAAT2 (156). Glutamate inhibition is the mechanism of riluzole, the first approved therapy for ALS. There is evidence for both central and peripheral immune system activation in ALS. In early disease, there is evidence of homeostatic microglia and Treg infiltration, while in later disease stages, M1 microglia and activated astrocytes predominate (157). Tregs themselves are defective in ALS $(99,100)$. TLR4, which activates microglia, is upregulated in the spinal cord of ALS patients, and could thereby mediate neurodegeneration (158). Immune-directed therapeutic trials to date have largely targeted microglia, and include minocycline, masitinib, NPO01 (a modulator of NF- $\kappa \mathrm{B}$ function on monocytes), and celecoxib. Of these, only masitinib, a tyrosine-kinase inhibitor targeting microglia and mast cells, has demonstrated positive results. Interim analysis showed that masitinib met both its primary endpoint, a change in the ALS function rating scale revised score, and its secondary endpoint, which included respiratory function and combined assessment of function and survival (159). Minocycline modulated microglial function and delayed disease progression in a mouse model of ALS but failed to demonstrate benefit in human studies. A potential explanation was later demonstrated in animal models: in later stages of ALS, in the setting of activated microglia, minocycline induces end-stage GFAP-biophotonic signals and increases connexin- 43 expression levels, thereby altering astrocyte function and inducing microgliosis (160). Edaravone is a free radical scavenger with antioxidant effects that was approved for ALS in the US in 2017 based on a small randomized controlled clinical trial with people with earlystage ALS in Japan. It failed two earlier trials in people with all stages of ALS. Other immune-directed strategies currently under investigation include ibudilast, anti-IL-6 (tocilizumab), and IL-1 receptor antagonist (anakinra) therapies (157). We have found that both microglia and peripheral monocytes have an inflammatory phenotype in the SOD model and in ALS and that targeting miR-155 ameliorates disease in this model (91); targeting of miR155 is now being evaluated in clinical trials.

Alzheimer's disease. $\mathrm{AD}$ is characterized by the presence of extracellular amyloid plaques, formed mainly from amyloid- $\beta(A \beta)$ 1-42 peptide and intracellular neurofibrillary tangles that contain hyperphosphorylated tau, both of which are neurotoxic. Additional pathological changes include gliosis, inflammation, neuritic dystrophy, neuronal loss, and changes in neurotransmitter levels. Solomon et al. demonstrated that monoclonal antibodies could dissolve $A \beta$ plaques in vitro $(161,162)$. Schenk et al. attenuated and prevented disease in $A \beta$-transgenic mice by administering $A \beta$ antibodies (163). Over the past 10 years, $A \beta$ immunotherapy has transitioned from preclinical studies to human studies, with at least 13 different trials stratified into passive antibody administration and active vaccination with $A \beta$. In the first vaccine trial, using AN1792A $\beta, 6 \%$ of patients developed meningoencephalitis (164), likely because of increased Th1 cell responses to A $\beta$ (165, 166). Eight vaccinated patients died, and autopsy examinations revealed profound reductions in amyloid load; however, they exhibited severe dementia at the time of death, suggesting that vaccination may not be sufficient to stop ongoing neurodegenerative processes. Newer active-immunization trials have either modified the $A \beta$ peptide to be less immunogenic or used only the B cell-reactive epitope (167).

At least seven trials using passive transfer of $A \beta$ antibodies have been performed. Post hoc analysis demonstrated marked cognitive benefits largely in patients who did not carry the apolipoprotein E (APOE) $\varepsilon 4$ allele; however, only a trend toward benefit was observed in APOE $\& 4$ carriers, possibly because of accelerated pathogenesis in these individuals (167). Vasogenic edema and cerebral hemorrhage have occurred in cases after passive anti-A $\beta$ immunotherapy (168). A large phase III clinical trial of the anti-amyloid antibody aducanumab is under way based on encouraging initial results (169).

Newer strategies for AD aim to enhance microglial phagocytosis of $\mathrm{A} \beta$, for instance by targeting TREM2 and CD33, but limit potentially deleterious microglial responses. We have found that nasal administration of a proteosome-based adjuvant (Protollin) induced monocytes that cleared fibrillar amyloid, insoluble $A \beta$, and soluble $A \beta$ fragments successfully in aged amyloid precursor protein-transgenic (APP-transgenic) mice (170). A clinical trial in AD subjects is planned.

\section{Lessons learned and future directions}

(a) Treat early: It is clear that immune-targeting therapeutics for MS and $\mathrm{AD}$ are most effective when targeting patients early in their disease course, when neurodegeneration and activation of secondary inflammatory pathways are not pronounced. Immunotherapy for $\mathrm{AD}$ has been more successful in earlier patients with minimal cognitive decline, but there is evidence from imaging that $\mathrm{A} \beta$ deposition has already occurred at this point (171).

(b) Different immune mechanisms predominate depending on the stage of disease and thus require different approaches: This is exemplified in ALS, in which minocycline was ineffective in the later stages of disease and may have even triggered astrogliosis in the setting of diffuse CNS inflammation. In MS, antiinflammatory medications have little effect in the secondary progressive phase of disease, which is mediated by innate and CNS-compartmentalized immune mechanisms.

(c) Microglia, macrophages, and astrocytes play important roles: As with T cell subsets, it is becoming clear that microglial, astrocyte, and macrophage subsets with unique molecular signatures can have both pathogenic and disease-ameliorating functions in neurodegeneration. Further work is required to elucidate the role of molecules involved in these subsets to target them therapeutically.

(d) Use caution in interpreting animal studies: One shortcoming of animal studies is the testing of therapies at early disease stages, which is unlike the situation in human clinical trials, where disease is only recognized in later stages. 
(e) Precision medicine approaches will enhance immunebased therapeutics: Given the heterogeneity of disease course as well as key pathogenic differences according to disease stage, precision approaches combining genomics, biomarkers, imaging markers, and targeted therapeutics may enhance immune-based management for CNS diseases.

In conclusion, inflammatory processes play an important role in neurodegeneration, both in triggering and amplifying degeneration and in providing avenues to limit neurodegeneration. Immune processes that impinge on neurodegeneration exist in both the periphery and the CNS. Because immune cells traffic to the CNS, some therapies can access periphery inflammatory processes to affect the CNS. It is more difficult to target local CNS inflammatory processes, such as microglia and astrocytes. It was recently shown that microglia (44) and astrocytes (172) may be affected by the microbiome, providing a potential new avenue to modulate CNS inflammation and degeneration.
It must be realized, however, that neurodegenerative processes may become inflammation-independent, especially in later stages. There is great promise in ongoing studies of inflammation-targeted neuroprotective strategies, which may ultimately be used across neurodegenerative diseases.

\section{Acknowledgments}

We thank the Ann Romney Center for Neurological Diseases for support of this work. We thank Belinda Kaskow for assistance with the figures.

Address correspondence to: Tanuja Chitnis or Howard L. Weiner, Ann Romney Center for Neurological Diseases, Partners Multiple Sclerosis Center, Department of Neurology, Brigham and Women's Hospital, Harvard Medical School, Boston, Massachusetts 02115, USA. Phone: 617.525.6550; Email: hweiner@rics.bwh.harvard.edu (H.L. Weiner); tchitnis@partners.org (T. Chitnis).
1. Ghavami S, et al. Autophagy and apoptosis dysfunction in neurodegenerative disorders. Prog Neurobiol. 2014;112:24-49.

2. Li SH, Lam S, Cheng AL, Li XJ. Intranuclear huntingtin increases the expression of caspase-1 and induces apoptosis. Hum Mol Genet. 2000;9(19):2859-2867.

3. Kiechle $\mathrm{T}$, et al. Cytochrome $\mathrm{C}$ and caspase- 9 expression in Huntington's disease. Neuromolecular Med. 2002;1(3):183-195.

4. Pasinelli P, Houseweart MK, Brown RH, Cleveland DW. Caspase- 1 and -3 are sequentially activated in motor neuron death in $\mathrm{Cu}, \mathrm{Zn}$ superoxide dismutase-mediated familial amyotrophic lateral sclerosis. Proc Natl Acad Sci U S A. 2000;97(25):13901-13906.

5. Garden GA, et al. Caspase cascades in human immunodeficiency virus-associated neurodegeneration. J Neurosci. 2002;22(10):4015-4024.

6. Re DB, et al. Necroptosis drives motor neuron death in models of both sporadic and familial ALS. Neuron. 2014;81(5):1001-1008.

7. Ito $\mathrm{Y}$, et al. RIPK1 mediates axonal degeneration by promoting inflammation and necroptosis in ALS. Science. 2016;353(6299):603-608.

8. Ofengeim D, et al. Activation of necroptosis in multiple sclerosis. Cell Rep. 2015;10(11):1836-1849.

9. Maiuri MC, Zalckvar E, Kimchi A, Kroemer G. Self-eating and self-killing: crosstalk between autophagy and apoptosis. Nat Rev Mol Cell Biol. 2007;8(9):741-752.

10. Hara T, et al. Suppression of basal autophagy in neural cells causes neurodegenerative disease in mice. Nature. 2006;441(7095):885-889.

11. Bauer PO, et al. Harnessing chaperone-mediated autophagy for the selective degradation of mutant huntingtin protein. Nat Biotechnol. 2010;28(3):256-263.

12. Vives-Bauza C, de Vries RL, Tocilescu M, Przedborski S. PINK1/Parkin direct mitochondria to autophagy. Autophagy. 2010;6(2):315-316.

13. Pickford F, et al. The autophagy-related protein beclin 1 shows reduced expression in early Alzheimer disease and regulates amyloid beta accumulation in mice. J Clin Invest. 2008;118(6):2190-2199.
14. Jangamreddy JR, et al. Salinomycin induces activation of autophagy, mitophagy and affects mitochondrial polarity: differences between primary and cancer cells. Biochim Biophys Acta. 2013;1833(9):2057-2069.

15. Isenmann S, Wahl C, Krajewski S, Reed JC, Bähr M. Up-regulation of Bax protein in degenerating retinal ganglion cells precedes apoptotic cell death after optic nerve lesion in the rat. Eur J Neurosci. 1997;9(8):1763-1772.

16. Garcia-Valenzuela E, Gorczyca W, Darzynkiewicz Z, Sharma SC. Apoptosis in adult retinal ganglion cells after axotomy. J Neurobiol. 1994;25(4):431-438.

17. Rabacchi SA, Bonfanti L, Liu XH, Maffei L. Apoptotic cell death induced by optic nerve lesion in the neonatal rat. J Neurosci. 1994;14(9):5292-5301.

18. Bondok AA, Sansone FM. Retrograde and transganglionic degeneration of sensory neurons after a peripheral nerve lesion at birth. Exp Neurol. 1984;86(2):322-330.

19. Egan DA, Flumerfelt BA, Gwyn DG. Axon reaction in the red nucleus of the rat. Perikaryal volume changes and the time course of chromatolysis following cervical and thoracic lesions. Acta Neuropathol. 1977;37(1):13-19.

20. Bjartmar C, Kinkel RP, Kidd G, Rudick RA, Trapp BD. Axonal loss in normal-appearing white matter in a patient with acute MS. Neurology. 2001;57(7):1248-1252.

21. Simon JH, Kinkel RP, Jacobs L, Bub L, Simonian N. A Wallerian degeneration pattern in patients at risk for MS. Neurology. 2000;54(5):1155-1160.

22. Simon JH, Jacobs L, Kinkel RP. Transcallosal bands: a sign of neuronal tract degeneration in early MS? Neurology. 2001;57(10):1888-1890.

23. Meyer-Franke A, Kaplan MR, Pfrieger FW, Barres BA. Characterization of the signaling interactions that promote the survival and growth of developing retinal ganglion cells in culture. Neuron. 1995;15(4):805-819.

24. Redford EJ, Kapoor R, Smith KJ. Nitric oxide donors reversibly block axonal conduction: demyelinated axons are especially susceptible. Brain. 1997;120(pt 12):2149-2157.

25. Brady ST, et al. Formation of compact myelin is required for maturation of the axonal cytoskeleton. J Neurosci. 1999;19(17):7278-7288.

26. Yin X, et al. Myelin-associated glycoprotein is a myelin signal that modulates the caliber of myelinated axons. J Neurosci. 1998;18(6):1953-1962.

27. Griffiths I, et al. Axonal swellings and degeneration in mice lacking the major proteolipid of myelin. Science. 1998;280(5369):1610-1613.

28. Bjartmar C, Yin X, Trapp BD. Axonal pathology in myelin disorders. J Neurocytol.1999; 28(4-5):383-395.

29. Kovacs GG, et al. Evaluating the patterns of aging-related tau astrogliopathy unravels novel insights into brain aging and neurodegenerative diseases. J Neuropathol Exp Neurol. 2017;76(4):270-288.

30. Ling $\mathrm{H}$, et al. Astrogliopathy predominates the earliest stage of corticobasal degeneration pathology. Brain. 2016;139(pt 12):3237-3252.

31. Lucchinetti CF, Guo Y, Popescu BF, Fujihara K, Itoyama Y, Misu T. The pathology of an autoimmune astrocytopathy: lessons learned from neuromyelitis optica. Brain Pathol. 2014;24(1):83-97.

32. Liddelow $S$, Barres B. SnapShot: astrocytes in health and disease. Cell. 2015;162(5):1170-1170.e1.

33. Werner P, Pitt D, Raine CS. Multiple sclerosis: altered glutamate homeostasis in lesions correlates with oligodendrocyte and axonal damage. Ann Neurol. 2001;50(2):169-180.

34. Rothstein JD, Van Kammen M, Levey AI, Martin LJ, Kuncl RW. Selective loss of glial glutamate transporter GLT-1 in amyotrophic lateral sclerosis. Ann Neurol. 1995;38(1):73-84.

35. Hardin-Pouzet H, Krakowski M, Bourbonnière L, Didier-Bazes M, Tran E, Owens T. Glutamate metabolism is down-regulated in astrocytes during experimental allergic encephalomyelitis. Glia. 1997;20(1):79-85.

36. Ben Haim L, Rowitch DH. Functional diversity of astrocytes in neural circuit regulation. Nat Rev Neurosci. 2017;18(1):31-41.

37. Molofsky AV, et al. Astrocyte-encoded positional cues maintain sensorimotor circuit integrity. Nature. 2014;509(7499):189-194.

38. Doyle JP, et al. Application of a translational profiling approach for the comparative analysis of 
CNS cell types. Cell. 2008;135(4):749-762.

39. Fouillet A, Mawson J, Suliman O, Sharrack B, Romero IA, Woodroofe MN. CCL2 binding is CCR2 independent in primary adult human astrocytes. Brain Res. 2012;1437:115-126.

40. Mayo L, et al. Regulation of astrocyte activation by glycolipids drives chronic CNS inflammation. Nat Med. 2014;20(10):1147-1156.

41. Liddelow SA, et al. Neurotoxic reactive astrocytes are induced by activated microglia. Nature. 2017;541(7638):481-487.

42. Lavin $\mathrm{Y}$, et al. Tissue-resident macrophage enhancer landscapes are shaped by the local microenvironment. Cell. 2014;159(6):1312-1326.

43. Gosselin D, et al. Environment drives selection and function of enhancers controlling tissue-specific macrophage identities. Cell. 2014;159(6):1327-1340.

44. Erny D, et al. Host microbiota constantly control maturation and function of microglia in the CNS. Nat Neurosci. 2015;18(7):965-977.

45. Prineas JW, Wright RG. Macrophages, lymphocytes, and plasma cells in the perivascular compartment in chronic multiple sclerosis. Lab Invest. 1978;38(4):409-421.

46. Filipowicz AR, et al. Proliferation of perivascular macrophages contributes to the development of encephalitic lesions in HIV-infected humans and in SIV-infected macaques. Sci Rep. 2016;6:32900.

47. Ginhoux F, et al. Fate mapping analysis reveals that adult microglia derive from primitive macrophages. Science. 2010;330(6005):841-845.

48. Schulz C, et al. A lineage of myeloid cells independent of Myb and hematopoietic stem cells. Science. 2012;336(6077):86-90.

49. Perdiguero EG, Geissmann F. The development and maintenance of resident macrophages. Nat Immunol. 2016;17(1):2-8.

50. Butovsky $\mathrm{O}$, et al. Identification of a unique TGF- $\beta$-dependent molecular and functional signature in microglia. Nat Neurosci. 2014;17(1):131-143.

51. Hickman SE, et al. The microglial sensome revealed by direct RNA sequencing. Nat Neurosci. 2013;16(12):1896-1905.

52. Chiu IM, et al. A neurodegeneration-specific gene-expression signature of acutely isolated microglia from an amyotrophic lateral sclerosis mouse model. Cell Rep. 2013;4(2):385-401.

53. Varol D, et al. Dicer deficiency differentially impacts microglia of the developing and adult brain. Immunity. 2017;46(6):1030-1044.e8.

54. Koeglsperger T, et al. Impaired glutamate recycling and GluN2B-mediated neuronal calcium overload in mice lacking TGF- $\beta 1$ in the CNS. Glia. 2013;61(6):985-1002.

55. Satoh J, et al. TMEM119 marks a subset of microglia in the human brain. Neuropathology. 2016;36(1):39-49.

56. Zrzavy T, Hametner S, Wimmer I, Butovsky O, Weiner HL, Lassmann H. Loss of 'homeostatic' microglia and patterns of their activation in active multiple sclerosis. Brain. 2017;140(7):1900-1913.

57. Biber K, Möller T, Boddeke E, Prinz M. Central nervous system myeloid cells as drug targets: current status and translational challenges. Nat Rev Drug Discov. 2016;15(2):110-124.
58. Ransohoff RM. A polarizing question: do M1 and M2 microglia exist? Nat Neurosci. 2016;19(8):987-991.

59. Bisht K, et al. Dark microglia: a new phenotype predominantly associated with pathological states. Glia. 2016;64(5):826-839.

60. Yamasaki R, et al. Differential roles of microglia and monocytes in the inflamed central nervous system. J Exp Med. 2014;211(8):1533-1549.

61. Spath S, et al. Dysregulation of the cytokine GM-CSF induces spontaneous phagocyte invasion and immunopathology in the central nervous system. Immunity. 2017;46(2):245-260.

62. Barclay AN, Clark MJ, McCaughan GW. Neuronal/lymphoid membrane glycoprotein MRC OX-2 is a member of the immunoglobulin superfamily with a light-chain-like structure. Biochem Soc Symp. 1986;51:149-157.

63. Wright GJ, et al. Lymphoid/neuronal cell surface OX2 glycoprotein recognizes a novel receptor on macrophages implicated in the control of their function. Immunity. 2000;13(2):233-242.

64. Preston S, Wright GJ, Starr K, Barclay AN, Brown $\mathrm{MH}$. The leukocyte/neuron cell surface antigen OX2 binds to a ligand on macrophages. Eur $J$ Immunol. 1997;27(8):1911-1918.

65. Hoek RM, et al. Down-regulation of the macrophage lineage through interaction with OX2 (CD200). Science. 2000;290(5497):1768-1771.

66. Liu Y, et al. CD200R1 agonist attenuates mechanisms of chronic disease in a murine model of multiple sclerosis. JNeurosci. 2010;30(6):2025-2038.

67. Chitnis T, et al. Elevated neuronal expression of CD200 protects Wlds mice from inflammation-mediated neurodegeneration. Am J Pathol. 2007;170(5):1695-1712.

68. Lunn ER, Perry VH, Brown MC, Rosen H, Gordon $\mathrm{S}$. Absence of wallerian degeneration does not hinder regeneration in peripheral nerve. Eur Neurosci. 1989;1(1):27-33.

69. Mack TG, et al. Wallerian degeneration of injured axons and synapses is delayed by a Ube $4 b /$ Nmnat chimeric gene. Nat Neurosci. 2001;4(12):1199-1206.

70. Perry VH, Brown MC, Lunn ER. Very Slow Retrograde and Wallerian Degeneration in the CNS of C57BL/Ola Mice. Eur JNeurosci. 1991;3(1):102-105

71. Ludwin SK, Bisby MA. Delayed wallerian degeneration in the central nervous system of Ola mice: an ultrastructural study. J Neurol Sci. 1992;109(2):140-147.

72. van Beek EM, Cochrane F, Barclay AN, van den Berg TK. Signal regulatory proteins in the immune system. J Immunol. 2005;175(12):7781-7787.

73. Okazawa H, et al. Negative regulation of phagocytosis in macrophages by the CD47-SHPS-1 system. JImmunol. 2005;174(4):2004-2011.

74. Kong XN, et al. LPS-induced down-regulation of signal regulatory protein $\{$ alpha\} contributes to innate immune activation in macrophages. JExp Med. 2007;204(11):2719-2731.

75. Latour S, et al. Bidirectional negative regulation of human $\mathrm{T}$ and dendritic cells by $\mathrm{CD} 47$ and its cognate receptor signal-regulator protein-alpha: down-regulation of IL-12 responsiveness and inhibition of dendritic cell activation. J Immunol. 2001;167(5):2547-2554

76. Smith RE, et al. A novel MyD-1 (SIRP-1 $\alpha$ ) signaling pathway that inhibits LPS-induced TNF- $\alpha$ production by monocytes. Blood. 2003;102(7):2532-2540.

77. Veillette A, Thibaudeau E, Latour S. High expression of inhibitory receptor SHPS- 1 and its association with protein-tyrosine phosphatase SHP-1 in macrophages. J Biol Chem. 1998;273(35):22719-22728.

78. Gresham HD, et al. Negative regulation of phagocytosis in murine macrophages by the Src kinase family member, Fgr.JExp Med. 2000;191(3):515-528.

79. Han MH, et al. Janus-like opposing roles of CD47 in autoimmune brain inflammation in humans and mice. JExp Med. 2012;209(7):1325-1334.

80. Guerreiro R, et al. TREM2 variants in Alzheimer's disease. N Engl JMed. 2013;368(2):117-127.

81. Jonsson T, et al. Variant of TREM2 associated with the risk of Alzheimer's disease. N Engl J Med. 2013;368(2):107-116

82. Guerreiro RJ, et al. Using exome sequencing to reveal mutations in TREM2 presenting as a frontotemporal dementia-like syndrome without bone involvement. JAMA Neurol. 2013;70(1):78-84.

83. Griciuc A, et al. Alzheimer's disease risk gene CD33 inhibits microglial uptake of amyloid beta. Neuron. 2013;78(4):631-643.

84. Naj AC, et al. Common variants at MS4A4/ MS4A6E, CD2AP, CD33 and EPHA1 are associated with late-onset Alzheimer's disease. Nat Genet. 2011;43(5):436-441.

85. Penberthy WT, Tsunoda I. The importance of NAD in multiple sclerosis. Curr Pharm Des. 2009;15(1):64-99.

86. Klein C, Grahnert A, Abdelrahman A, Muller CE, Hauschildt S. Extracellular NAD(+) induces a rise in $[\mathrm{Ca}(2+)]$ (i) in activated human monocytes via engagement of P2Y(1) and P2Y(11) receptors. Cell Calcium. 2009;46(4):263-272.

87. Moore CS, et al. P2Y12 expression and function in alternatively activated human microglia. Neurol Neuroimmunol Neuroinflamm. 2015;2(2):e80.

88. Carrieri PB, Provitera V, De Rosa T, Tartaglia G, Gorga F, Perrella O. Profile of cerebrospinal fluid and serum cytokines in patients with relapsing-remitting multiple sclerosis: a correlation with clinical activity. Immunopharmacol Immunotoxicol. 1998;20(3):373-382.

89. Codarri L, et al. ROR $\gamma \mathrm{t}$ drives production of the cytokine GM-CSF in helper T cells, which is essential for the effector phase of autoimmune neuroinflammation. Nat Immunol. 2011;12(6):560-567.

90. Ambros V. The functions of animal microRNAs. Nature. 2004;431(7006):350-355.

91. Butovsky O, et al. Targeting miR-155 restores abnormal microglia and attenuates disease in SOD1 mice. Ann Neurol. 2015;77(1):75-99.

92. Cho KJ, Song J, Oh Y, Lee JE. MicroRNA-Let-7a regulates the function of microglia in inflammation. Mol Cell Neurosci. 2015;68:167-176.

93. Zhang L, Dong LY, Li YJ, Hong Z, Wei WS. The microRNA miR-181c controls microglia-mediated neuronal apoptosis by suppressing tumor necrosis factor. J Neuroinflammation. 2012;9:211.

94. Melzer N, Meuth SG, Wiendl H. CD8 ${ }^{+}$T cells and neuronal damage: direct and collateral mechanisms of cytotoxicity and impaired electrical excitability. FASEB J. 2009;23(11):3659-3673. 
95. Meuth SG, et al. Cytotoxic $\mathrm{CD}^{+} \mathrm{T}$ cell-neuron interactions: perforin-dependent electrical silencing precedes but is not causally linked to neuronal cell death. J Neurosci. 2009;29(49):15397-15409.

96. Melzer N, et al. Excitotoxic neuronal cell death during an oligodendrocyte-directed $\mathrm{CD} 8^{+} \mathrm{T}$ cell attack in the CNS gray matter. J Neuroinflammation. 2013;10:121.

97. Brochard V, et al. Infiltration of $\mathrm{CD}^{+}$lymphocytes into the brain contributes to neurodegeneration in a mouse model of Parkinson disease. JClin Invest. 2009;119(1):182-192.

98. Costantino CM, Baecher-Allan C, Hafler DA. Multiple sclerosis and regulatory T cells. JClin Immunol. 2008;28(6):697-706.

99. Zhao W, Beers DR, Liao B, Henkel JS, Appel SH. Regulatory T lymphocytes from ALS mice suppress microglia and effector T lymphocytes through different cytokine-mediated mechanisms. Neurobiol Dis. 2012;48(3):418-428.

100.Beers DR, et al. ALS patients' regulatory T lymphocytes are dysfunctional, and correlate with disease progression rate and severity. JCI Insight. 2017;2(5):e89530.

101.Sea K, et al. Insights into the role of the unusual disulfide bond in copper-zinc superoxide dismutase. J Biol Chem. 2015;290(4):2405-2418.

102. Therrien M, Dion PA, Rouleau GA. ALS: Recent Developments from Genetics Studies. Curr Neurol Neurosci Rep. 2016;16(6):59.

103. Al-Chalabi A, Jones A, Troakes C, King A, Al-Sarraj S, van den Berg LH. The genetics and neuropathology of amyotrophic lateral sclerosis. Acta Neuropathol. 2012;124(3):339-352.

104.Dalkara T, Endres M, Moskowitz MA. Mechanisms of NO neurotoxicity. Prog Brain Res. 1998;118:231-239.

105. Dawson VL, Dawson TM. Nitric oxide in neurodegeneration. Prog Brain Res. 1998;118:215-229.

106. Bal-Price A, Brown GC. Inflammatory neurodegeneration mediated by nitric oxide from activated glia-inhibiting neuronal respiration, causing glutamate release and excitotoxicity. J Neurosci. 2001;21(17):6480-6491.

107. Brown GC, Bal-Price A. Inflammatory neurodegeneration mediated by nitric oxide, glutamate, and mitochondria. Mol Neurobiol. 2003;27(3):325-355.

108. Chao CC, Hu S, Sheng WS, Bu D, Bukrinsky MI, Peterson PK. Cytokine-stimulated astrocytes damage human neurons via a nitric oxide mechanism. Glia. 1996;16(3):276-284.

109. Combs CK, Karlo JC, Kao SC, Landreth GE. beta-Amyloid stimulation of microglia and monocytes results in TNFalpha-dependent expression of inducible nitric oxide synthase and neuronal apoptosis. JNeurosci. 2001;21(4):1179-1188.

110. Hallam DM, Capps NL, Travelstead AL, Brewer GJ, Maroun LE. Evidence for an interferon-related inflammatory reaction in the trisomy 16 mouse brain leading to caspase-1-mediated neuronal apoptosis. J Neuroimmunol. 2000;110(1-2):66-75.

111. Hemmer K, Fransen L, Vanderstichele H, Vanmechelen E, Heuschling P. An in vitro model for the study of microglia-induced neurodegeneration: involvement of nitric oxide and tumor necrosis factor-alpha. Neurochem Int.
2001;38(7):557-565.

112. Bal-Price A, Moneer Z, Brown GC. Nitric oxide induces rapid, calcium-dependent release of vesicular glutamate and ATP from cultured rat astrocytes. Glia. 2002;40(3):312-323.

113. Gunasekar PG, Kanthasamy AG, Borowitz JL, Isom GE. NMDA receptor activation produces concurrent generation of nitric oxide and reactive oxygen species: implication for cell death. J Neurochem. 1995;65(5):2016-2021.

114. Dawson TM, Zhang J, Dawson VL, Snyder SH. Nitric oxide: cellular regulation and neuronal injury. Prog Brain Res. 1994;103:365-369.

115. Chang CI, Liao JC, Kuo L. Arginase modulates nitric oxide production in activated macrophages. Am J Physiol. 1998;274(1 pt 2):H342-H348.

116. Smith KJ, Kapoor R, Hall SM, Davies M. Electrically active axons degenerate when exposed to nitric oxide. Ann Neurol. 2001;49(4):470-476.

117. Redford EJ, Kapoor R, Smith KJ. Nitric oxide donors reversibly block axonal conduction: demyelinated axons are especially susceptible. Brain. 1997;120(pt 12):2149-2157.

118. Okuda Y, et al. Expression of the inducible isoform of nitric oxide synthase in the central nervous system of mice correlates with the severity of actively induced experimental allergic encephalomyelitis. J Neuroimmunol.1995;62(1):103-112.

119. Kennedy MK, Torrance DS, Picha KS, Mohler KM. Analysis of cytokine mRNA expression in the central nervous system of mice with experimental autoimmune encephalomyelitis reveals that IL-10 mRNA expression correlates with recovery. J Immunol. 1992;149(7):2496-2505.

120. Bauer J, Berkenbosch F, Van Dam AM, Dijkstra CD. Demonstration of interleukin-1 beta in Lewis rat brain during experimental allergic encephalomyelitis by immunocytochemistry at the light and ultrastructural level. J Neuroimmunol. 1993;48(1):13-21.

121. Stroemer RP, Rothwell NJ. Exacerbation of ischemic brain damage by localized striatal injection of interleukin-1 $\beta$ in the rat. J Cereb Blood Flow Metab. 1998;18(8):833-839.

122. Yang GY, Zhao YJ, Davidson BL, Betz AL. Overexpression of interleukin-1 receptor antagonist in the mouse brain reduces ischemic brain injury. Brain Res. 1997;751(2):181-188.

123. Downen M, Amaral TD, Hua LL, Zhao ML, Lee SC. Neuronal death in cytokine-activated primary human brain cell culture: role of tumor necrosis factor- $\alpha$. Glia. 1999;28(2):114-127.

124. Chao CC, Lokensgard JR, Sheng WS, Hu S, Peterson PK. IL-1-induced iNOS expression in human astrocytes via NF-кB. Neuroreport. 1997;8(14):3163-3166.

125. Stoll G, Jander S, Schroeter M. Cytokines in CNS disorders: neurotoxicity versus neuroprotection. J Neural Transm Suppl. 2000;59:81-89.

126. Matsuoka I, Meyer M, Thoenen H. Cell-type-specific regulation of nerve growth factor (NGF) synthesis in non-neuronal cells: comparison of Schwann cells with other cell types. J Neurosci. 1991;11(10):3165-3177.

127. Carlson NG, Wieggel WA, Chen J, Bacchi A, Rogers SW, Gahring LC. Inflammatory cytokines IL-1 $\alpha$, IL-1 $\beta$, IL-6, and TNF- $\alpha$ impart neuroprotection to an excitotoxin through distinct path- ways. JImmunol. 1999;163(7):3963-3968.

128. Moroni SC, Rossi A. Enhanced survival and differentiation in vitro of different neuronal populations by some interleukins. Int J Dev Neurosci. 1995;13(1):41-49.

129. Araujo DM, Cotman CW. Trophic effects of interleukin-4, -7 and -8 on hippocampal neuronal cultures: potential involvement of glial-derived factors. Brain Res. 1993;600(1):49-55.

130. Rothwell NJ, Strijbos PJ. Cytokines in neurodegeneration and repair. Int J Dev Neurosci. 1995;13(3-4):179-185.

131. Chavany C, Vicario-Abejón C, Miller G, Jendoubi M. Transgenic mice for interleukin 3 develop motor neuron degeneration associated with autoimmune reaction against spinal cord motor neurons. Proc Natl Acad Sci U S A. 1998;95(19):11354-11359.

132. Chiang CS, Powell HC, Gold LH, Samimi A, Campbell IL. Macrophage/microglial-mediated primary demyelination and motor disease induced by the central nervous system production of interleukin-3 in transgenic mice. J Clin Invest. 1996;97(6):1512-1524.

133. Campbell IL, et al. Neurologic disease induced in transgenic mice by cerebral overexpression of interleukin 6. Proc Natl Acad Sci US A. 1993;90(21):10061-10065.

134. Heyser CJ, Masliah E, Samimi A, Campbell IL, Gold LH. Progressive decline in avoidance learning paralleled by inflammatory neurodegeneration in transgenic mice expressing interleukin 6 in the brain. Proc Natl Acad Sci US A. 1997;94(4):1500-1505.

135. Bettelli E, et al. Reciprocal developmental pathways for the generation of pathogenic effector TH17 and regulatory T cells. Nature. 2006;441(7090):235-238.

136. Erta M, Quintana A, Hidalgo J. Interleukin-6, a major cytokine in the central nervous system. Int J Biol Sci. 2012;8(9):1254-1266.

137. Taupin V, Renno T, Bourbonnière L, Peterson AC, Rodriguez M, Owens T. Increased severity of experimental autoimmune encephalomyelitis, chronic macrophage/microglial reactivity, and demyelination in transgenic mice producing tumor necrosis factor- $\alpha$ in the central nervous system. Eur JImmunol. 1997;27(4):905-913.

138. Probert L, Akassoglou K, Pasparakis M, Kontogeorgos G, Kollias G. Spontaneous inflammatory demyelinating disease in transgenic mice showing central nervous system-specific expression of tumor necrosis factor alpha. Proc Natl Acad Sci US A. 1995;92(24):11294-11298.

139. Wilde GJ, Pringle AK, Sundstrom LE, Mann DA, Iannotti F. Attenuation and augmentation of ischaemia-related neuronal death by tumour necrosis factor- $\alpha$ in vitro. Eur J Neurosci. 2000;12(11):3863-3870.

140.Venters HD, Tang Q, Liu Q, VanHoy RW, Dantzer $\mathrm{R}$, Kelley KW. A new mechanism of neurodegeneration: a proinflammatory cytokine inhibits receptor signaling by a survival peptide. Proc Natl Acad Sci U S A. 1999;96(17):9879-9884.

141. Liu J, et al. TNF is a potent anti-inflammatory cytokine in autoimmune-mediated demyelination. Nat Med.1998;4(1):78-83.

142.Arnett HA, Mason J, Marino M, Suzuki K, Matsu- 
shima GK, Ting JP. TNF alpha promotes proliferation of oligodendrocyte progenitors and remyelination. Nat Neurosci. 2001;4(11):1116-1122.

143. van Beek J, et al. Complement anaphylatoxin C3a is selectively protective against NMDA-induced neuronal cell death. Neuroreport. 2001;12(2):289-293.

144. Osaka H, Mukherjee P, Aisen PS, Pasinetti GM. Complement-derived anaphylatoxin C5a protects against glutamate-mediated neurotoxicity. JCell Biochem. 1999;73(3):303-311.

145. Farkas I, et al. A neuronal C5a receptor and an associated apoptotic signal transduction pathway. J Physiol (Lond). 1998;507(pt 3):679-687.

146.Davoust N, Jones J, Stahel PF, Ames RS, Barnum SR. Receptor for the C3a anaphylatoxin is expressed by neurons and glial cells. Glia. 1999;26(3):201-211.

147. Lucchinetti CF, et al. A role for humoral mechanisms in the pathogenesis of Devic's neuromyelitis optica. Brain. 2002;125(pt 7):1450-1461.

148. Lucchinetti C, Brück W, Parisi J, Scheithauer B, Rodriguez M, Lassmann H. Heterogeneity of multiple sclerosis lesions: implications for the pathogenesis of demyelination. Ann Neurol. 2000;47(6):707-717.

149. Weiner HL. The challenge of multiple sclerosis: how do we cure a chronic heterogeneous disease? Ann Neurol. 2009;65(3):239-248.

150. Dolgin E. Therapies: progressive steps. Nature. 2016;540(7631):S7-S9.

151. Rothhammer V, et al. Sphingosine 1-phosphate receptor modulation suppresses pathogenic astrocyte activation and chronic progressive CNS inflammation. Proc Natl Acad Sci U S A. 2017;114(8):2012-2017.

152. Choi JW, et al. FTY720 (fingolimod) efficacy in an animal model of multiple sclerosis requires astrocyte sphingosine 1-phosphate receptor 1 (S1P1) modulation. Proc Natl Acad Sci U S A. 2011;108(2):751-756.

153. Montalban X, et al. Ocrelizumab versus Placebo in Primary Progressive Multiple Sclerosis. N Engl JMed. 2017;376(3):209-220.

154.Fox RJ, et al. Design, rationale, and baseline characteristics of the randomized double-blind phase II clinical trial of ibudilast in progressive multiple sclerosis. Contemp Clin Trials. 2016;50:166-177.

155. Taylor JP, Brown RH, Cleveland DW. Decoding ALS: from genes to mechanism. Nature. 2016;539(7628):197-206.

156. Lin CL, et al. Aberrant RNA processing in a neurodegenerative disease: the cause for absent EAAT2, a glutamate transporter, in amyotrophic lateral sclerosis. Neuron. 1998;20(3):589-602.

157. Crisafulli SG, Brajkovic S, Cipolat Mis MS, Parente V, Corti S. Therapeutic strategies under development targeting inflammatory mechanisms in amyotrophic lateral sclerosis [published online ahead of print April 28, 2017]. Mol Neurobiol. https://doi.org/10.1007/s12035-017-0532-4.

158. Casula $\mathrm{M}$, et al. Toll-like receptor signaling in amyotrophic lateral sclerosis spinal cord tissue. Neuroscience. 2011;179:233-243.

159. Petrov D, Mansfield C, Moussy A, Hermine O. ALS Clinical Trials Review: 20 years of failure. Are we any closer to registering a new treatment? Front Aging Neurosci. 2017;9:68.

160. Keller AF, Gravel M, Kriz J. Treatment with minocycline after disease onset alters astrocyte reactivity and increases microgliosis in SOD1 mutant mice. Exp Neurol. 2011;228(1):69-79.

161. Solomon B, Koppel R, Hanan E, Katzav T. Monoclonal antibodies inhibit in vitro fibrillar aggregation of the Alzheimer $\beta$-amyloid peptide. Proc Natl Acad Sci U S A. 1996;93(1):452-455.
162.Solomon B, Koppel R, Frankel D, Hanan-Aharon E. Disaggregation of Alzheimer $\beta$-amyloid by site-directed mAb. Proc Natl Acad Sci U S A. 1997;94(8):4109-4112.

163. Schenk D, et al. Immunization with amyloid-beta attenuates Alzheimer-disease-like pathology in the PDAPP mouse. Nature. 1999;400(6740):173-177.

164. Orgogozo JM, et al. Subacute meningoencephalitis in a subset of patients with $\mathrm{AD}$ after $\mathrm{A} \beta 42$ immunization. Neurology. 2003;61(1):46-54.

165.Zota V, et al. HLA-DR alleles in amyloid beta-peptide autoimmunity: a highly immunogenic role for the DRB1*1501 allele. J Immunol. 2009;183(5):3522-3530.

166. Monsonego A, et al. Increased T cell reactivity to amyloid beta protein in older humans and patients with Alzheimer disease. JClin Invest. 2003;112(3):415-422.

167. Lemere CA, Masliah E. Can Alzheimer disease be prevented by amyloid-beta immunotherapy? Nat Rev Neurol. 2010;6(2):108-119.

168. Pfeifer M, et al. Cerebral hemorrhage after passive anti-Abeta immunotherapy. Science. 2002;298(5597):1379.

169.Sevigny J, et al. The antibody aducanumab reduces A $\beta$ plaques in Alzheimer's disease. Nature. 2016;537(7618):50-56.

170.Frenkel D, et al. A nasal proteosome adjuvant activates microglia and prevents amyloid deposition. Ann Neurol. 2008;63(5):591-601.

171. Sperling RA, et al. The A4 study: stopping AD before symptoms begin? Sci Transl Med. 2014;6(228):228fs13.

172. Rothhammer V, et al. Type I interferons and microbial metabolites of tryptophan modulate astrocyte activity and central nervous system inflammation via the aryl hydrocarbon receptor. Nat Med. 2016;22(6):586-597. 